九州大学学術情報リポジトリ

Kyushu University Institutional Repository

\title{
Study on Water-Vapor Adsorption onto Polymer and Carbon Based Adsorbents for Air- Conditioning Applications
}

Mahmood, Muhammad Hamid

Department of Agricultural Engineering, Bahauddin Zakariya University

Sultan, Muhammad

Department of Agricultural Engineering, Bahauddin Zakariya University

Miyazaki, Takahiko

Faculty of Engineering Sciences, Kyushu University : Professor

https://doi.org/10.5109/2349297

出版情報：Evergreen. 6 (3)，pp.215-224，2019-09. 九州大学グリーンテクノロジー研究教育センター バージョン：

権利関係 : 


\title{
Study on Water-Vapor Adsorption onto Polymer and Carbon Based Adsorbents for Air-Conditioning Applications
}

\author{
Muhammad Hamid Mahmood ${ }^{1}$, Muhammad Sultan ${ }^{1, *}$, Takahiko Miyazaki ${ }^{2,3}$ \\ ${ }^{1}$ Department of Agricultural Engineering, Bahauddin Zakariya University, Bosan Road, Multan 60800, Pakistan \\ ${ }^{2}$ Faculty of Engineering Sciences, Kyushu University, Kasuga-koen 6-1, Kasuga-shi, Fukuoka 816-8580, Japan \\ ${ }^{3}$ International Institute for Carbon-Neutral Energy Research (WPI-I ${ }^{2}$ CNER), Kyushu University, 744 Motooka, \\ Nishi-ku, Fukuoka 819-0395, Japan
}

\begin{abstract}
*Author to whom correspondence should be addressed:
E-mail: muhammadsultan@bzu.edu.pk ; sultan@kyudai.jp
\end{abstract}

(Received July 9, 2019; accepted August 30, 2019)

\begin{abstract}
Carbon-based materials have shown huge potential in various adsorption based applications e.g. water and wastewater treatment. In addition, these are successfully utilized for various (methanol-, ethanol-, and ammonia-based) closed-cycle adsorption heat pump systems. Significance of polymers is also well-known in drug/medical industry, and therefore extensively studied for various aspects of adsorption. The study comprises two kinds of polymer and carbonbased materials for potential air-conditioning applications. Water vapor adsorption comparison has been made among polymer, carbon-based and conventional hydrophilic adsorbent i.e. silica-gel. The size of desiccant unit in desiccant air-conditioning (DAC) system has been determined and compared accordingly. Results showed that polymer sorbent (PS-II) can reduce the desiccant unit size (in the DAC system) by 2-3 times as compare to conventional silica-gel under particular conditions while utilizing it intelligently.
\end{abstract}

Keywords: adsorbents, hydrophilic polymer, desiccant, air-conditioning, applications.

\section{Introduction}

The vital need for heating, ventilation, and airconditioning for human thermal comfort is well known in the literature. Many designs of such systems have also been investigated for various applications like conventional vapor compression air-conditioning (VAC) for residential, commercial, institutional and office buildings, data center cooling, electronics cooling, manufacturing and storage processes ${ }^{1}$. However, the effective farm level applications of these systems have not been much explored in the literature. The farm-level applications may include (i) air-conditioning (AC) for human (farm residents/workers) thermal comfort, (ii) AC for farm livestock thermal comfort, (iii) $\mathrm{AC}$ for farm greenhouse, and (iv) AC for pre-cooling and storage of farm produce etc. The conventional vapor compression refrigeration and/or air-conditioning systems are not only responsible for high energy requirements and environmental pollution but also cannot be used to provide optimal storage conditions to the agricultural products (e.g. mango, tomato, leafy vegetables etc.) due to chilling injury, discoloration and off-flavor ${ }^{2-6}$. Moreover, these systems are not best suited to control the latent and sensible load of greenhouse environment ${ }^{7-10)}$. The complex mechanism of transpiration, respiration, fermentation in agricultural products and photosynthesis, evapotranspiration in growing greenhouse plants required active consideration about the provisions of ventilation rate, temperature and relative humidity control ${ }^{4,9}$. On the other hand, the much higher ventilation rate is required in animal houses to remove the odors and ammonia. It may go up to maximum 60 air changes per hour in order to maintain the indoor air quality, temperature, and relative humidity ${ }^{11}$. The ammonia is most dangerous and chronic contaminant gas produced within the animal house due to the decomposition of manure ${ }^{11)}$. The conventional vapor compression refrigeration and/or air-conditioning systems are considered unfeasible and/or uneconomical for animal houses ${ }^{11)}$ that might be due to the requirements of higher ventilation rate. The high ventilation rate is essential to maintain the indoor air quality by removing odor, ammonia, and heat. Therefore, there is dire need of low cost, environment-friendly air-conditioning system/package that can be effectively employed for all farm-level applications. In this regard, evaporative cooling technologies like direct evaporative cooling (DEC), indirect evaporative cooling (IEC)/M-Cycle 
evaporative cooling (MEC) have shown potential for farm-level applications ${ }^{4,8,9)}$. However, these technologies do not perform efficiently under largely varying ambient conditions (particularly humid) due to limited cooling performance. The scope of DEC and IEC/MEC for various agricultural applications under varying environmental condition can be extended by the integration of desiccant dehumidification. The desiccant air-conditioning (DAC) comprises of desiccant dehumidification cum evaporative cooling has ability to deal the latent and sensible load of air-conditioning distinctly. It also gives opportunity to operate it by low grade waste heat, and renewable energy options like solar energy (particularly solar thermal) bio-gas, bio-diesel, etc. Therefore, the energy and environmental friendly DAC system represent zero global warming and ozone depletion potentials. In this regard, lots of practical airconditioning systems based on desiccant has been established and working all over the world. Mostly studied desiccant air-conditioning systems are standalone DAC systems with aid of simplified heat exchangers, direct and/or indirect evaporative cooling assisted DAC systems, vapor compression based hybrid DAC systems, solar energy operated DAC systems, bio-gas operated DAC systems, single/multi-stage DAC systems, solid/liquidbased DAC systems, wheel/block-based DAC systems, heat and pressure regeneration based DAC systems and many more. Such characteristics of the DAC system make it promising for the widespread applications like agricultural product storage/preservation, greenhouses, marine ships, wet markets, automobiles, buildings, museums, hospitals (etc.) ${ }^{12-21)}$.

In the preview of above discussion, it is ascertained that the DAC system can be a promising solution for farmlevel air-conditioning applications. Additionally, it can be operated by harvesting renewable energy sources (solar energy, bio-gas, bio-diesel, etc.) abundantly available at the farm. The details about the typical system operation can be found in reference ${ }^{9)}$.

\section{Scope of the study}

The desiccant air-conditioning despite energy saving and eco-friendly technology still could not break the barriers for its market penetration. The main barriers are high initial cost, long payback period and system size ${ }^{22)}$. One of the main components in DAC system is a desiccant unit by which system size and operational cost are associated. There is dire need of research for the development of small size, low cost, non-toxic and noncorrosive adsorbent bed. The adsorbent should have high adsorption uptake with higher adsorption kinetics. In this regard, adsorbent materials can play role towards the optimization of DAC system size. The significance of adsorbents is obvious for various technological, medical and engineering applications. Physiochemical and thermodynamic properties of adsorbents have been effectively realized for various adsorption based applications e.g. wastewater treatment, adsorption heat pump systems, etc. Carbon-based materials have shown huge potentials in numerous adsorption applications particularly for water and wastewater treatment. It has been also successfully utilized for various (methanol-, ethanol-, and ammonia-based) close cycle adsorption heat pump systems. However, the present study focused on the open cycle desiccant air-conditioning. Therefore, the study comprises two kinds of polymer and carbon-based materials for potential air-conditioning applications. Water vapor adsorption comparison has been made among polymer \& carbon-based materials and conventional hydrophilic adsorbent i.e. silica-gel. The size of desiccant unit in desiccant air-conditioning system has been determined and compared accordingly.

\section{Materials and method}

\subsection{Materials}

The study comprises different adsorbents such as polymer-based, carbon-based, and conventional silica-gel. The polymer-based adsorbents include polymer sorbent-I (PS-I), polymer sorbent-II (PS-II) ${ }^{23-25)}$. The carbon-based adsorbents include activated carbon powder (ACP) and activated carbon fiber (ACF) ${ }^{7,8,26)}$. The particle size of these adsorbents is given in Table $1^{7,8,23,24)}$. All these adsorbents have specific adsorption characteristics. Silicagel is mostly used in the designing of DAC systems due to its strong affinity towards water ${ }^{22)}$. The silica-gel has higher bulk density than PS-I but less than PS-II. It has been determined that the PS-II possesses about 1.5 times higher bulk density than PS-I and about 1.16 times higher than silica-gel ${ }^{23)}$. It is important to mention that the density of adsorbent is crucial towards the optimization of system size for different applications. The microscopic images of few particles of PS-I and PS-II particles are shown in Fig. 1(a) and (b), respectively ${ }^{7,23)}$. The illustration these of materials into desiccant block, desiccant rotor, desiccant coated heat exchangers is shown in the same Fig. 1. The carbon-based adsorbents (ACP, ACF) also have typical properties. The ACP is a highly porous adsorbent, whereas, ACF as a fibrous adsorbent possesses high porosity, and ease in handling ${ }^{8)}$. 


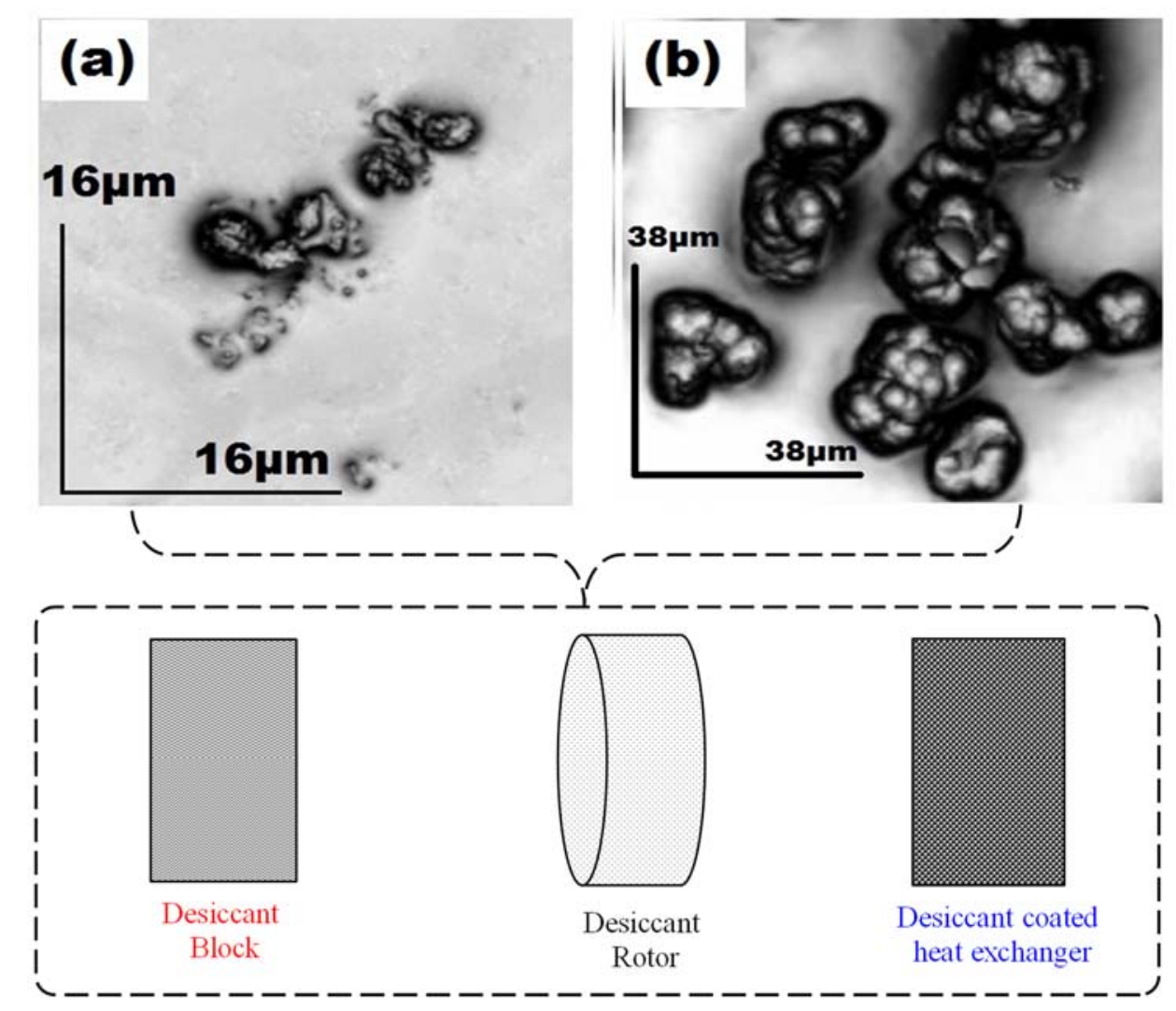

Fig. 1: Microscopic image of few particles of (a) PS-I, and (b) PS-II ${ }^{7,23)}$

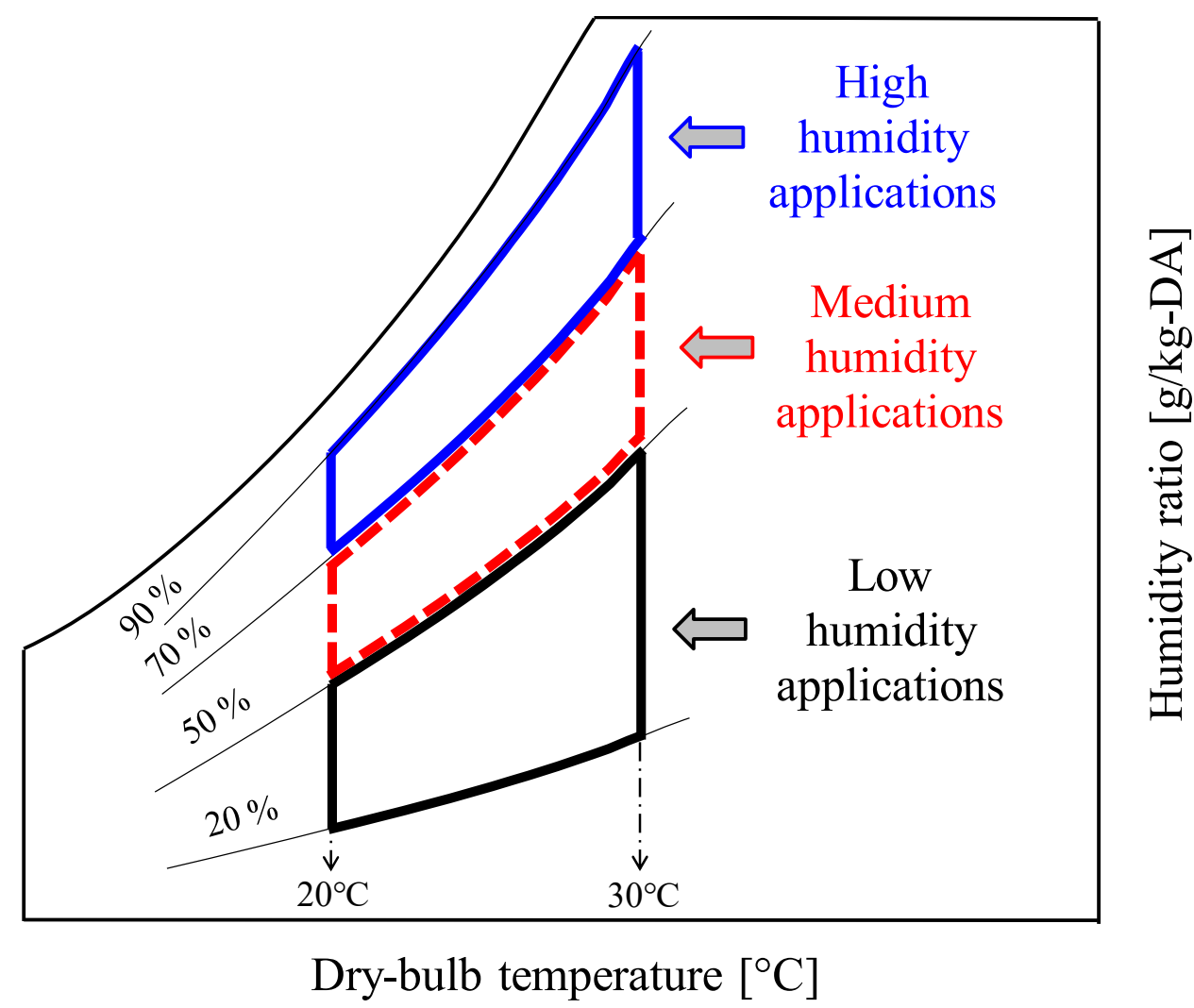

Fig. 2: Psychrometric representation of different humidity applications 


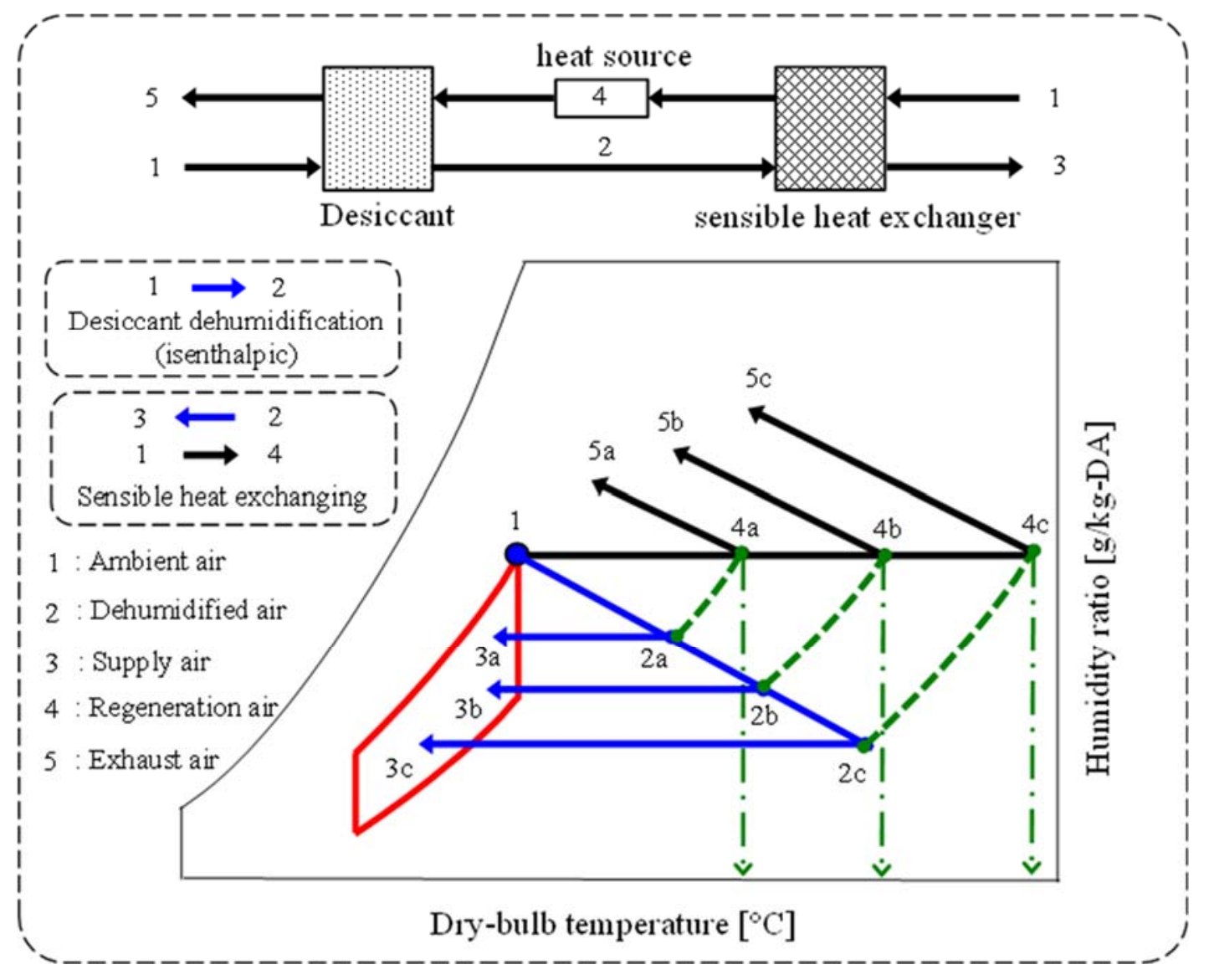

Fig. 3: Schematic of the DAC system with the psychrometric representation of ideal DAC cycle for medium humidity applications

Table 1. The particle diameter of studied adsorbents ${ }^{7,8,23,24)}$

\begin{tabular}{lc}
\hline Adsorbents & $\begin{array}{c}\text { Particle diameter } \\
(\mu \mathrm{m})\end{array}$ \\
\hline PS-I $^{23,24)}$ & 2.6 \\
PS-II $^{23,24)}$ & 19.3 \\
$\mathrm{ACF}^{7,8)}$ & 13.0 \\
$\mathrm{ACP}^{7,8)}$ & 105 \\
Silica-gel $^{7,8)}$ & 1000 \\
\hline
\end{tabular}

\subsection{Data analysis and procedure}

The isotherm plots of adsorbents (Table 1) are drawn and compared in order to determine the adsorption uptake at a respective temperature on the basis of data from references ${ }^{7,8,23-26)}$. The isosteric heat of adsorption $\left(\mathrm{Q}_{\mathrm{st}}\right)$ is also compared for PS-I, PS-II and silica-gel ${ }^{7,23)}$. The performance of the adsorption heat pump systems (e.g. DAC system) mainly depends upon the amount of $\mathrm{Q}_{\text {st. }}$. Moreover, the contribution of the polymeric material towards the system size reduction is investigated in comparison to conventional silica-gel. In this regard, the adsorbent to air mass fraction $\left(\mathrm{MF}_{\mathrm{A}-\mathrm{A}}\right)$ is calculated by the following relationship ${ }^{8,10)}$.

$$
\mathrm{MF}_{\mathrm{A}-\mathrm{A}}=\left(\frac{\Delta \mathrm{W}}{\Delta \mathrm{M}}\right)_{\Delta \mathrm{RH}}=\left(\frac{\mathrm{W}_{1}-\mathrm{W}_{2}}{\mathrm{M}_{1}-\mathrm{M}_{2}}\right)_{\Delta \mathrm{RH}}
$$

where, $\mathrm{MF}_{\mathrm{A}-\mathrm{A}}$ describes the adsorbent to air mass fraction $\left(\mathrm{g}_{\mathrm{ads}} / \mathrm{kg}_{\mathrm{DA}}\right), \mathrm{W}_{1}$ and $\mathrm{W}_{2}$ are the humidity ratios $\left(\mathrm{g}_{\mathrm{H} 2 \mathrm{O}} / \mathrm{kg}_{\mathrm{DA}}\right), \mathrm{M}_{1}$ and $\mathrm{M}_{2}$ are the adsorption uptakes $\left(\mathrm{g}_{\mathrm{H} 2 \mathrm{O}} / \mathrm{g}_{\mathrm{ads}}\right) . \mathrm{MF}_{\mathrm{A}-\mathrm{A}}$ of the adsorbents (PS-I, PS-II, silicagel) is calculated for high, medium and low humidity applications/conditions. The psychrometric representation of these applications is shown in Fig. 2. The ambient air (T, RH) is considered the same for all the adsorbents (PSI, PS-II, Silica-gel) in the respective humidity application. The state (1) in Fig. 3 represents the ambient air for medium humidity applications. Moreover, the states $(2,3,4,5)$ represents the different stages of the simplified typical DAC cycle for different levels $(a, b, c)$ of dehumidification and regeneration. The process/ambient air (1) becomes dehumidified as it passes through the adsorbents. The dehumidified air (2) is further passed 


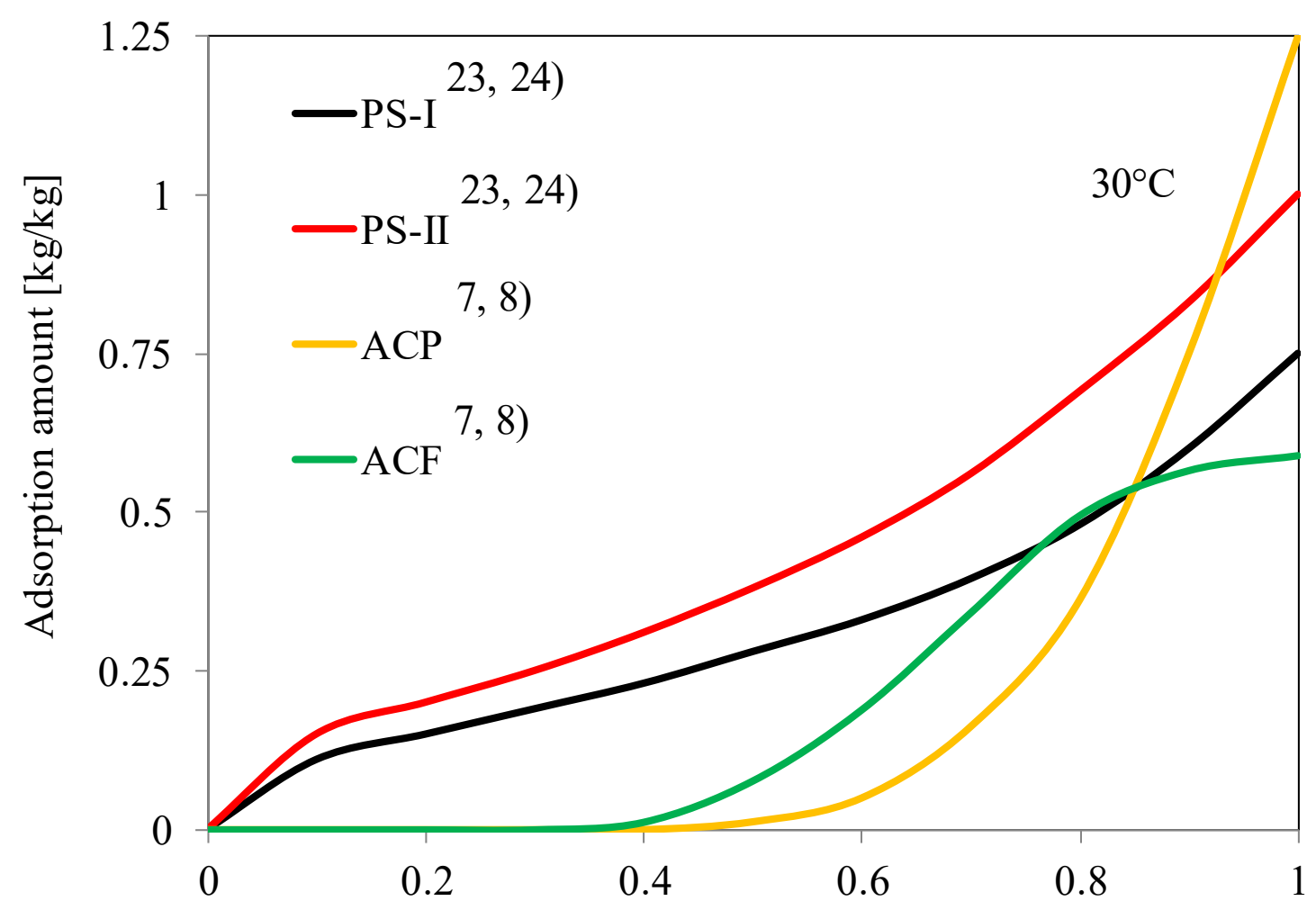

(a)

Relative humidity, $\mathrm{P}_{\mathrm{a}} / \mathrm{P}_{\mathrm{s}}[-]$

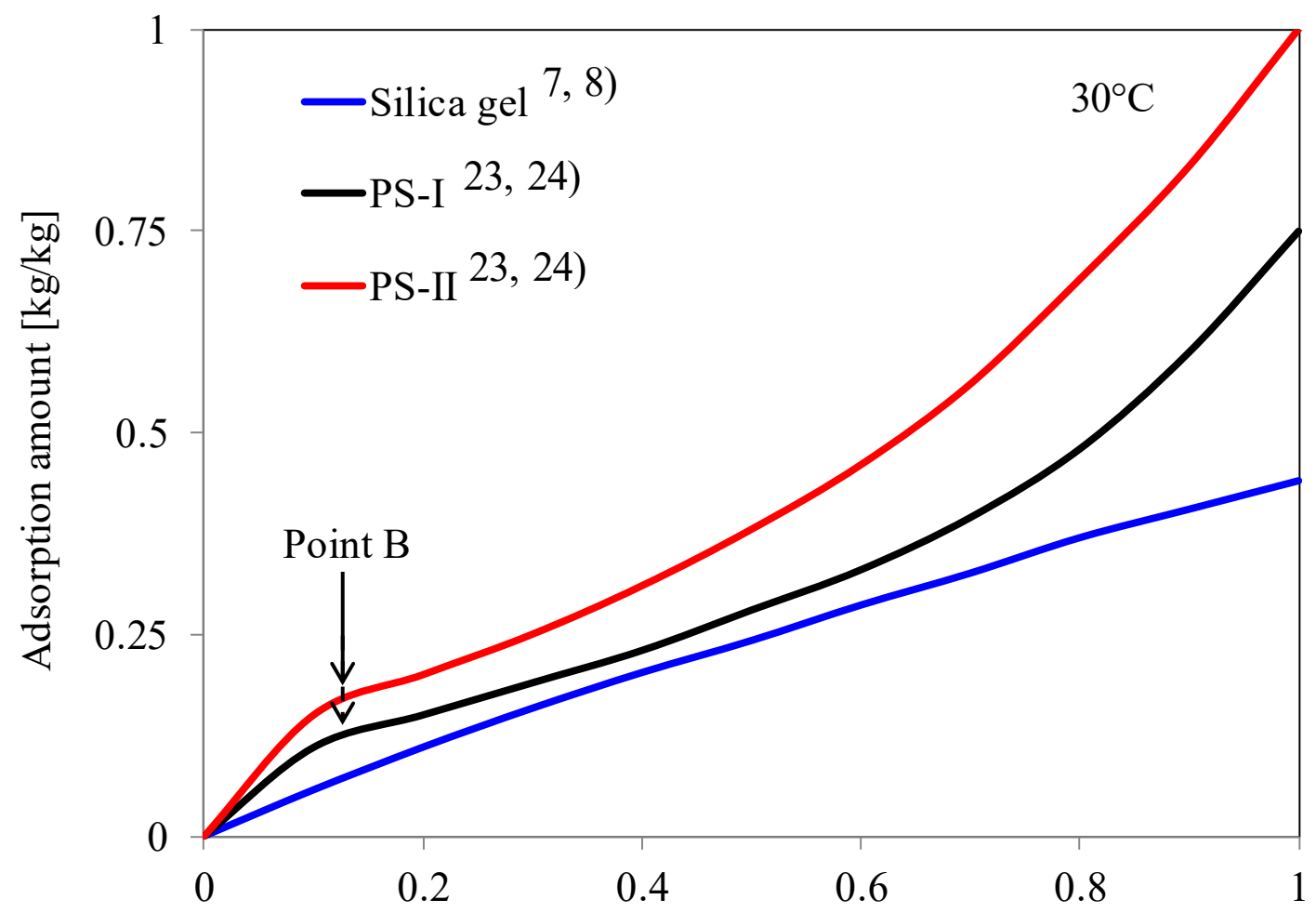

(b)

Relative humidity, $\mathrm{P}_{\mathrm{a}} / \mathrm{P}_{\mathrm{s}}[-]$

Fig. 4: Comparison of adsorption isotherms at $30^{\circ} \mathrm{C}$ for (a) PS-I, PS-II, ACP, ACF; (b) PS-I and PS-II with Silica-gel 


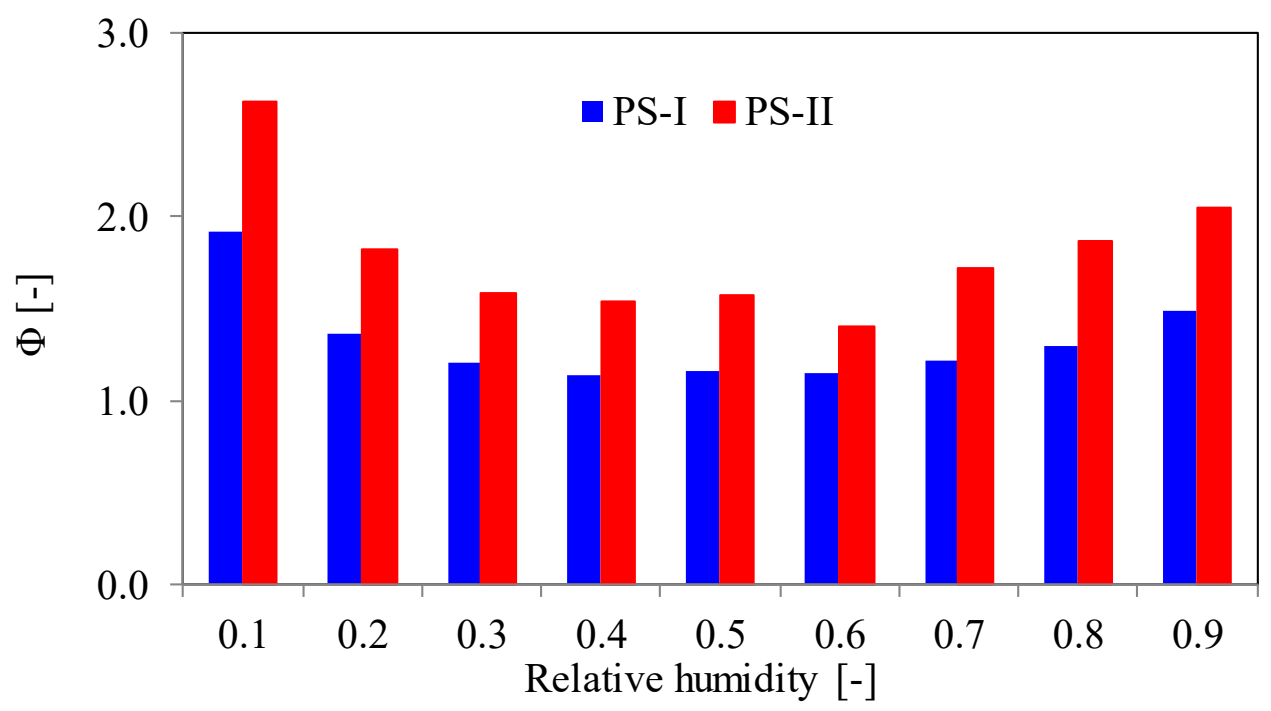

Fig. 5: Adsorption uptake fraction of adsorbents over silica-gel

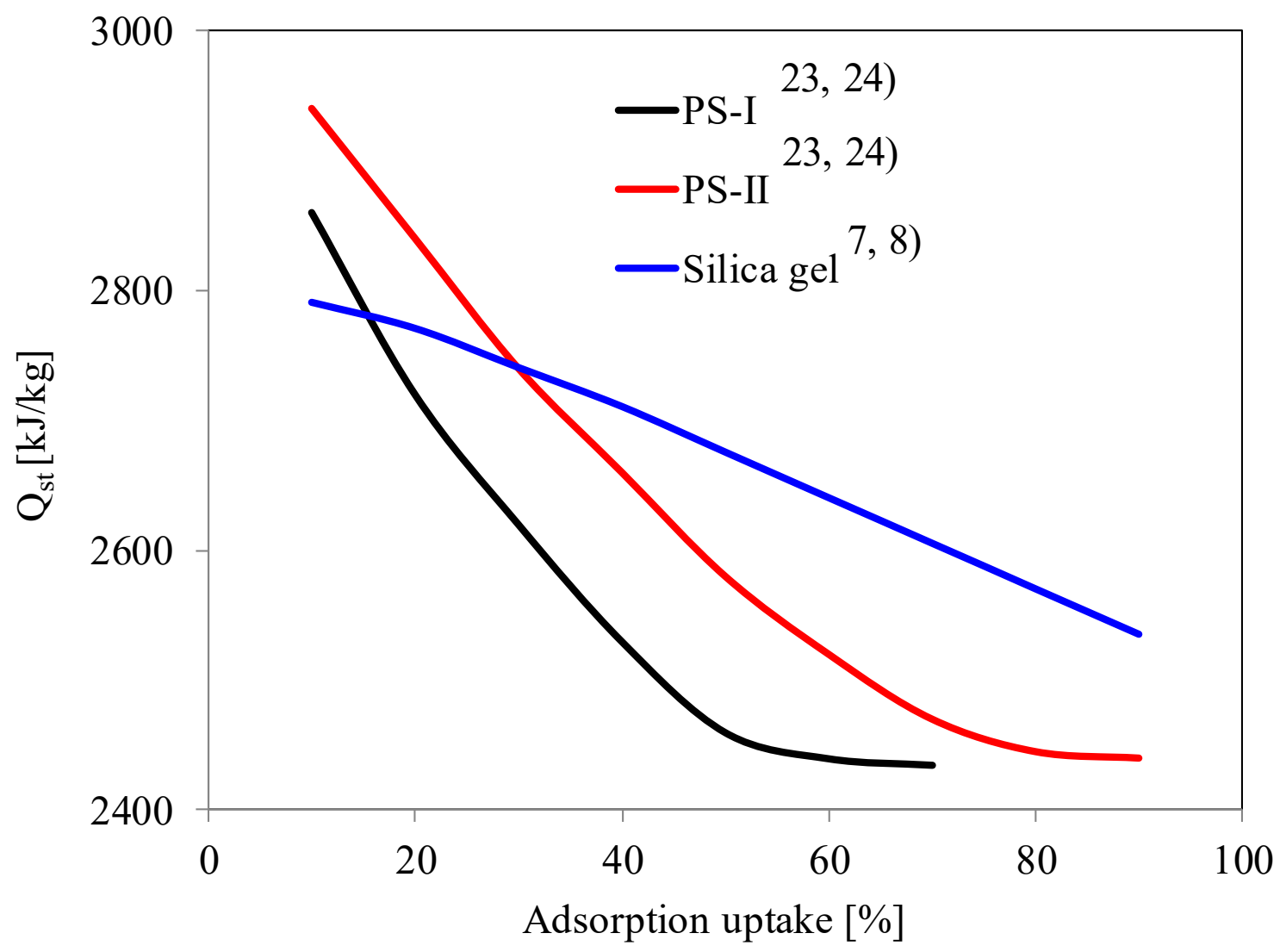

Fig. 6: Comparison of isosteric heat of adsorption of PS-I and PS-II with silica-gel

through the sensible heat exchanger and/or evaporative coolers to supply the conditioned air. On the regeneration side, the same ambient air (1) is used for the purpose. The regeneration air becomes hot by exchanging heat (via heat exchanger) with the process air. This hot regeneration air is then further heated (state 4) through external heat 
source to pass it through the adsorbent and finally exhaust (state 5) to the environment.

The psychrometric evaluation of thermal comfort zones for human and livestock, ideal growth zone for the agricultural greenhouse, and ideal storage zones for agricultural products revealed that all these applications required certain level of latent and sensible load of airconditioning. In this regard DAC has shown potential to control the latent and sensible load of AC distinctly ${ }^{4,6,7,22)}$.

\section{Results and discussion}

The water vapor adsorption isotherms are drawn in Fig. 4(a) using the data available in the literature for two carbon and two polymer-based materials in comparison with silica-gel ${ }^{8,23)}$. It can be noticed that carbon-based adsorbents i.e. ACP and ACF shows hydrophobic behavior at low relative pressure range, therefore may be neglected for further investigation. However, it is important to mention that such kind of water vapor adsorption might be interesting for various high humiditybased DAC applications e.g. agricultural greenhouses, storage of fresh fruits and likewise. This kind of adsorption is based on water vapor condensation using multilayer adsorption phenomena [19]. The water vapor adsorption isotherms of ACP and ACF resemble the IUPAC type-III and type-V isotherms, respectively. Therefore, further investigation in this study is focused on PS-I and PS-II. In this regard, the adsorbents are compared with conventional silica-gel distinctly as depicted in Fig. 4(b). It can be seen from Fig. 4(b) that the water vapor adsorption uptake by silica-gel at saturation conditions (on $30^{\circ} \mathrm{C}$ ) is about $0.40 \mathrm{~kg} / \mathrm{kg}$. But, the adsorption uptake by PS-I and PS-II under the same conditions is almost 2.0 and 2.5 times higher than silicagel adsorption uptake, respectively ${ }^{7)}$. It is noticed that the isotherms of both the PS-I and PS-II have concave shape at the start (lower relative pressure) and then turned to convex shape as the relative pressure increases. Such shape of isotherms is due to two principal classes/fractions of the sorbed water ${ }^{23,27)}$. The first is bound water on the inner/outer surface of the adsorbent by the forces in excess of the normal forces which results in concave shape ${ }^{23,27}$. The second fraction is responsible for convex shape because it is normally condensed within the adsorbent as the function of relative pressure ${ }^{23,27)}$. The summation of these fractions results in sigmoid shape polymer isotherms 23,27). It is worthy to mention that the sigmoid shape isotherms of polymeric material (PS-I and PS-II) are important for the designing of open-cycle desiccant airconditioning systems. Moreover, the bar graphs are shown in Fig. 5 mainly represent the adsorption uptake fraction (Ф) of PS-I and PS-II over silica-gel.

The adsorption amount of PS-I and PS-II are divided by the adsorption amounts of the silica-gel in order to determine the $\Phi_{\text {PS-I }}$ and $\Phi_{\text {PS-II }}$, respectively. It can be seen from Fig. 5 that $\Phi_{\text {PS-II }}$ is higher than the $\Phi_{\text {PS-I }}$ over the entire range of relative humidity. Therefore, it leads towards better adsorption performance by PS-II under varying relative humidity conditions. The $\mathrm{Q}_{\mathrm{st}}$ of the polymer adsorbents (PS-I, PS-II) and conventional silicagel is also compared (Fig. 6) in order to further investigate the insights about these adsorbents. It represents the strength of adsorbent-refrigerant interaction and the performance of the adsorption heat pump systems mainly depend on it.
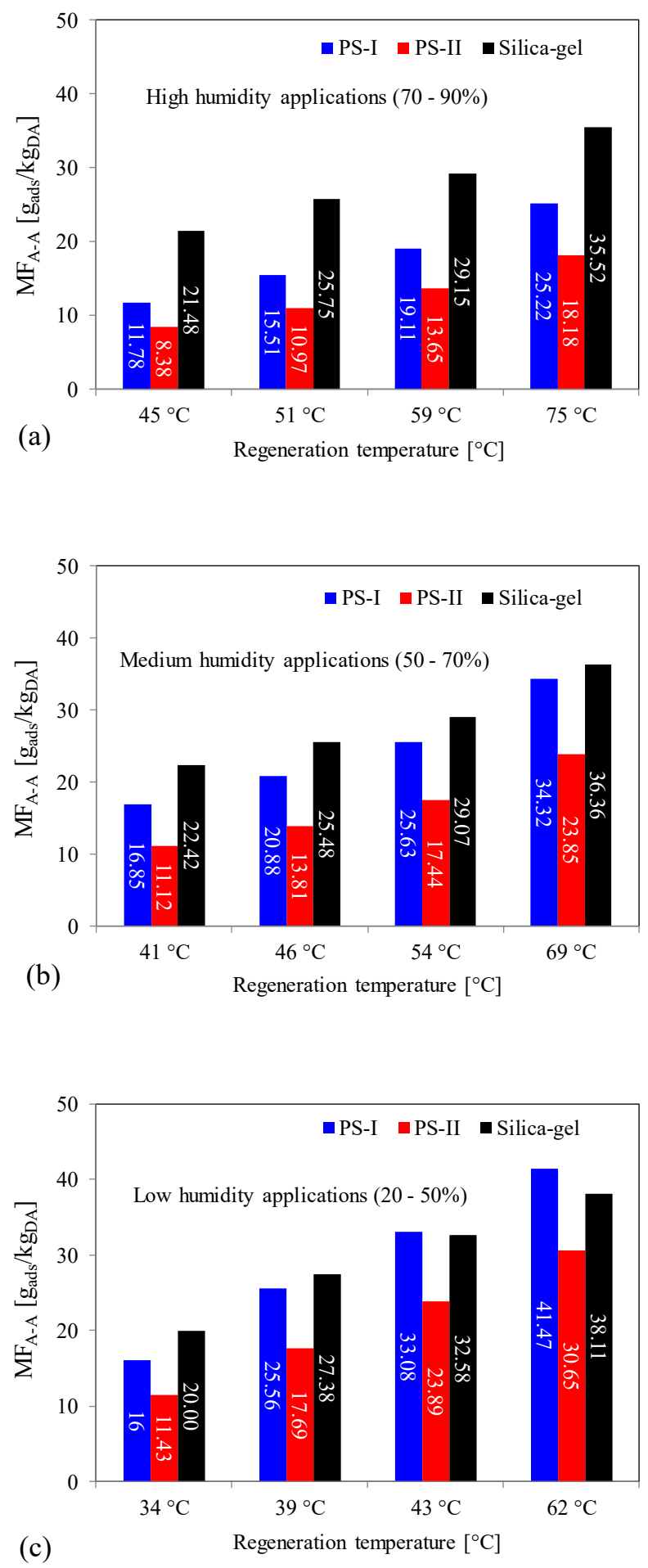

Fig. 7: The adsorbent to air mass fraction under varying 
regeneration temperature for (a) high; (b) medium; and (c) low humidity condition.

The $\mathrm{Q}_{\text {st }}$ of the silica-gel largely varies as compare to PSI and PS-II (Fig. 6). However, in case of PS-I and PS-II the isosteric heat of adsorption decreases relatively rapidly than silica-gel. Therefore, it can be concluded from this detailed discussion that the PS-I and PS-II can be potential adsorbents for the optimization of DAC system. The contribution of the polymeric material (PS-I $\&$ II) towards the system size reduction is investigated in comparison to conventional silica-gel using Eq. 1 as shown in Fig. 7. It can be noticed that the $\mathrm{MF}_{\mathrm{A}-\mathrm{A}}$ increases with increasing regeneration temperature for all the adsorbents and under all humidity applications as shown in Figs. 7(a-c). It is determined that the $\mathrm{MF}_{\mathrm{A}-\mathrm{A}}$ for PS-II is well lower than silica-gel as compare to PS-I. In this regard, it can be envisaged that the PS-II can dehumidify the same amount of air with 2-3 times less adsorbent as compare to silica-gel under particular regeneration temperature. Therefore, the utilization of polymeric material (PS-II) can leads towards the reduction in system size by 2-3 times under particular conditions as far as desiccant unit is concerned. Moreover, the nano/micro polymeric materials can be shaped into honeycomb-like structure (desiccant block, desiccant rotor, desiccant coated heat exchangers, etc.). These materials can be regenerated at low temperature, therefore, gives opportunity to use the solar energy (preferably solar thermal), bio-gas and bio-diesel (etc.). Thus, the compactsized DAC system can be operated more economically for different applications by performing regeneration through renewable energy sources ${ }^{28)}$.

\section{Conclusions}

This study provides water vapor adsorption comparison among different polymer \& carbon-based materials and conventional hydrophilic adsorbent, silica gel. The studied polymeric and carbon adsorbents include the PSI, PS-II, ACP, and ACF. It is investigated that ACP and ACF show hydrophobic behavior at low relative pressure range, however such kind of water vapor adsorption might be interesting for various high humidity-based DAC applications e.g. agricultural greenhouses, storage of agricultural products and likewise. It is concluded that PSII reduces the desiccant unit size (in the DAC system) by 2-3 times as compared to conventional silica-gel under particular conditions. Moreover, polymeric adsorbents facilitate low temperature regeneration, providing an opportunity to run the system on renewable energy sources. The study focused on fundamental guidelines for various air-conditioning applications and therefore will be worthy for the researchers/scientists working for the development of advanced polymer-based nano or micro materials.

\section{Acknowledgments}

The authors would like to acknowledge the support from Professor Shigeru Koyama (Ph.D.), who, although no longer with us, continues to inspire by his example of hardworking and dedication to the students he served over the course of his career.

\section{Nomenclature}

$\begin{array}{ll}A C & \text { air-conditioning } \\ \mathrm{ACF} & \text { activated carbon fiber } \\ \mathrm{ACP} & \text { activated carbon powder } \\ \mathrm{DAC} & \text { desiccant air-conditioning } \\ M & \text { adsorption uptakes }\left[\mathrm{g}_{\mathrm{H} 2 \mathrm{O}} / \mathrm{g}_{\text {ads }}\right] \\ M F_{A-A} & \text { adsorbent to air mass fraction }\left[\mathrm{g}_{\mathrm{ads}} / \mathrm{kg}_{\mathrm{DA}}\right] \\ P_{a} & \text { partial vapor pressure }[\mathrm{kPa}] \\ P_{s} & \text { saturation vapor pressure }[\mathrm{kPa}] \\ \mathrm{PS} & \text { polymer sorbent } \\ Q_{s t} & \text { isosteric heat of adsorption }[\mathrm{kJ} / \mathrm{kg}] \\ R H & \text { relative humidity }[\%] \text { or }[-] \\ T & \text { temperature }\left[{ }^{\circ} \mathrm{C} \text { or } \mathrm{K}\right] \\ W & \text { humidity ratio }\left[\mathrm{g}_{\mathrm{H} 2 \mathrm{O}} / \mathrm{kg} \mathrm{DA}\right] \\ \Phi & \text { adsorbents adsorption uptake fraction over } \\ & \text { silica-gel } \\ D A & \text { dry air } \\ a d s & \text { adsorbent }\end{array}$

\section{References}

1) M.H. Mahmood, M. Sultan, T. Miyazaki, S. Koyama, and V.S. Maisotsenko, "Overview of the maisotsenko cycle - a way towards dew point evaporative cooling," Renew. Sustain. Energy Rev., $66 \quad 537-555 \quad$ (2016). doi:10.1016/j.rser.2016.08.022.

2) M.C. Ndukwu, and S.I. Manuwa, "Impact of evaporative cooling preservation on the shelf life of fruits and vegetable in south western nigeria," Res. Agric. Eng., 61 (3) 122-128 (2015). doi:10.17221/54/2013-RAE.

3) W.A. Olosunde, A.K. Aremu, and D.I. Onwude, "Development of a solar powered evaporative cooling storage system for tropical fruits and vegetables," J. Food Process. Preserv., 40 (2) 279-290 (2016). doi:10.1111/jfpp.12605.

4) M.H. Mahmood, M. Sultan, T. Miyazaki, and S. Koyama, "Desiccant air-conditioning system for storage of fruits and vegetables: pakistan preview," Evergreen, 3 (1) 12-17 (2016). doi:10.5109/1657381.

5) M.H. Mahmood, "Investigation of desiccant airconditioning and evaporative cooling systems for agricultural storage applications," Kyushu University, Japan, 2017.

6) M.H. Mahmood, M. Sultan, T. Miyazaki, and S. Koyama, "Theoretical and experimental analysis of desiccant air conditioning system for storage of 
agricultural products," in: Int. Refrig. Air Cond. Conf., Purdue University, USA, 2016: pp. 1-10.

7) M. Sultan, "Study on sorption characteristics of water adsorbents for agricultural air-conditioning systems," Kyushu University, Japan, 2015. doi:10.15017/1544017.

8) M. Sultan, T. Miyazaki, B.B. Saha, and S. Koyama, "Steady-state investigation of water vapor adsorption for thermally driven adsorption based greenhouse air-conditioning system," Renew. Energy, $86 \quad 785-795 \quad$ (2016). doi:10.1016/J.RENENE.2015.09.015.

9) M. Sultan, and T. Miyazaki, "Energy-efficient airconditioning systems for nonhuman applications,' in: O. Ekren (Ed.), Refrigeration, InTech, 2017: pp. 97-117. doi:10.5772/intechopen.68865.

10) M. Sultan, I.I. El-Sharkawy, T. Miyazaki, B.B. Saha, and S. Koyama, "Experimental study on carbon based adsorbents for greenhouse dehumidification," Evergreen, 1 (2) 5-11 (2014). doi:10.5109/1495157.

11) ASHRAE, "Handbook-HVAC Applications," American Society of Heating, Refrigerating and Air-conditioning Engineers, Inc., Atlanta, 2007.

12) N. Enteria, H. Yoshino, A. Mochida, R. Takaki, A. Satake, R. Yoshie, T. Mitamura, and S. Baba, "Construction and initial operation of the combined solar thermal and electric desiccant cooling system," Sol. Energy, 83 (8) 1300-1311 (2009). doi:10.1016/J.SOLENER.2009.03.008.

13) N. Enteria, H. Yoshino, A. Satake, A. Mochida, R. Takaki, R. Yoshie, and S. Baba, "Development and construction of the novel solar thermal desiccant cooling system incorporating hot water production," Appl. Energy, 87 (2) 478-486 (2010). doi:10.1016/J.APENERGY.2009.08.026.

14) G.A. Longo, and A. Gasparella, "Three years experimental comparative analysis of a desiccant based air conditioning system for a flower greenhouse: assessment of different desiccants," Appl. Therm. Eng., 78 584-590 (2015). doi:10.1016/J.APPLTHERMALENG.2014.12.00 5.

15) K. Nagaya, T. Senbongi, Y. Li, J. Zheng, and I. Murakami, "High energy efficiency desiccant assisted automobile air-conditioner and its temperature and humidity control system," Appl. Therm. Eng., 26 (14-15) 1545-1551 (2006). doi:10.1016/J.APPLTHERMALENG.2005.12.00 5 .

16) J. Zhu, and W. Chen, "Energy and exergy performance analysis of a marine rotary desiccant air-conditioning system based on orthogonal experiment," Energy, 77 953-962 (2014). doi:10.1016/J.ENERGY.2014.10.014.

17) Z. Guojie, Z. Chaoyu, Y. Guanghai, and C. Wu, "Development of a new marine rotary desiccant airconditioning system and its energy consumption analysis," Energy Procedia, 16 1095-1101 doi:10.1016/J.EGYPRO.2012.01.175.

18) F. Ascione, L. Bellia, A. Capozzoli, and F. Minichiello, "Energy saving strategies in airconditioning for museums," Appl. Therm. Eng., 29 (4) 676-686 (2009). doi:10.1016/J.APPLTHERMALENG.2008.03.04 0 .

19) F. Ascione, L. Bellia, and A. Capozzoli, "A coupled numerical approach on museum air conditioning: energy and fluid-dynamic analysis," Appl. Energy, 103 416-427 (2013). doi:10.1016/J.APENERGY.2012.10.007.

20) S.H. Lee, and W.L. Lee, "Site verification and modeling of desiccant-based system as an alternative to conventional air-conditioning systems for wet markets," Energy, 55 1076-1083 (2013). doi:10.1016/J.ENERGY.2013.04.029.

21) C. Renno, D. D’Agostino, F. Minichiello, F. Petito, and I. Balen, "Performance analysis of a cpv/t-dc integrated system adopted for the energy requirements of a supermarket," Appl. Therm. Eng., 149 (May 2018) 231-248 (2019). doi:10.1016/j.applthermaleng.2018.12.007.

22) M. Sultan, I.I. El-Sharkawy, T. Miyazaki, B.B. Saha, and S. Koyama, "An overview of solid desiccant dehumidification and air conditioning systems," Renew. Sustain. Energy Rev., 46 16-29 (2015). doi:10.1016/j.rser.2015.02.038.

23) M. Sultan, I.I. El-Sharkawy, T. Miyazaki, B.B. Saha, S. Koyama, T. Maruyama, S. Maeda, and T. Nakamura, "Insights of water vapor sorption onto polymer based sorbents," Adsorption, 21 (3) 205 215 (2015). doi:10.1007/s10450-015-9663-y.

24) M. Sultan, I.I. El-Sharkawy, T. Miyazaki, B.B. Saha, S. Koyama, T. Maruyama, S. Maeda, and T. Nakamura, "Water vapor sorption kinetics of polymer based sorbents: theory and experiments," Appl. Therm. Eng., 106 192-202 (2016). doi:10.1016/J.APPLTHERMALENG.2016.05.19 2.

25) M. Sultan, T. Miyazaki, S. Koyama, and Z.M. Khan, "Performance evaluation of hydrophilic organic polymer sorbents for desiccant airconditioning applications," Adsorpt. Sci. Technol., $36 \quad(1-2) \quad 311-326 \quad$ (2018). doi:10.1177/0263617417692338.

26) M. Sultan, T. Miyazaki, and S. Koyama, "Optimization of adsorption isotherm types for desiccant air-conditioning applications," Renew. Energy, $121 \quad 441-450 \quad$ (2018). doi:10.1016/J.RENENE.2018.01.045.

27) S.E. Smith, and S.E. Smith, "The sorption of water vapor by high polymers," J. Am. Chem. Soc., (1947). doi:10.1021/ja01195a053. 
28) M.H. Mahmood, M. Sultan, and T. Miyazaki, "Solid desiccant dehumidification-based airconditioning system for agricultural storage application: theory and experiments," Proc. Inst. Mech. Eng. Part A J. Power Energy, 0 (0) (2019). doi:10.1177/0957650919869503. 